\title{
Serum zinc and copper levels in a sample of Egyptian epileptic children
}

\author{
Mona A. Eissa 1*, Khaled O. Abdulghani', Maha A. Nada², Hala M. Elkhawas ${ }^{2}$, Ahmed E. Shouman ${ }^{3}$ and
} Nahed S. Ahmed ${ }^{2}$

\begin{abstract}
Background: Epilepsy is among the most common disabling neurological disorders among children. Altered serum levels of zinc and copper may facilitate seizure occurrence and repetition, and antiepileptic drugs may disturb their serum levels affecting disease control and outcome.

Objective: To investigate the association between serum levels of zinc and copper and epilepsy and antiepileptic treatment in a group of Egyptian epileptic children.

Methods: Case-control study on 100 epileptic patients, aged from 2 to 16 years, from neurology outpatient clinic and 50 apparently healthy children with matched age and sex. Venous samples were withdrawn from patients and controls then serum levels of zinc and copper were measured with graphite furnace atomic absorption spectrometer-A Analyst 800.

Results: Serum zinc level of patients' group was significantly lower than that of controls with a mean of $59.1 \mu / \mathrm{dL}$ \pm 22.7 and $85 \mu / \mathrm{dL} \pm 22.2$, respectively $(P<0.01)$. Serum zinc level of patients with history of febrile seizures was significantly decreased compared to patients without history of febrile seizures with a mean of $41.5 \mu / \mathrm{dL} \pm 20.1$ and $67.9 \mu / \mathrm{dL} \pm 19.3$, respectively $(P<0.01)$. Patient on carbamazepine intake showed significantly lower zinc serum level than patients without carbamazepine intake, with a mean of $49.0 \mu / \mathrm{dL} \pm 17$ and $61.8 \mu / \mathrm{dL} \pm 23.4$, respectively $(P<0.01)$. A significant negative correlation was noted between the duration of illness of epilepsy and the mean copper serum level $(P<0.05)$.
\end{abstract}

Conclusion: Zinc and copper altered homeostasis have mounting evidence about their role in the pathogenesis of epilepsy. Designing treatment plans that selectively restore zinc and copper normal levels may be a beneficial strategy in the future.

Keywords: Epilepsy, Children, Trace elements, Zinc, Copper

\section{Introduction}

Epilepsy is the third leading contributor to the global burden of disease for neurological disorders [1]. Among the population with newly diagnosed epilepsy, children and older adults are the most rapidly growing segments [2].

Childhood epilepsy has a large spectrum of clinical manifestations and many different causes [3]. A history

\footnotetext{
* Correspondence: eissamona1@gmail.com

'Departemnt of Neurology and Psychiatry, Helwan University School of Medicine, Cairo, Egypt

Full list of author information is available at the end of the article
}

of complex febrile seizures is frequently correlated with a risk of epilepsy developing in the future [4]. Childhood epilepsy often has a fluctuating course, and approximately one third of epileptic children experience alternating periods of seizure freedom and seizure relapses. About 59\% of children with epilepsy can achieve reasonably good seizure control with antiepileptic drug therapy, and around $30 \%$ will be refractory despite numerous medications [5].

Certain minerals and trace elements are essential for the development of healthy nervous system and

\section{Springer Open}

(- The Author(s). 2020 Open Access This article is licensed under a Creative Commons Attribution 4.0 International License, which permits use, sharing, adaptation, distribution and reproduction in any medium or format, as long as you give appropriate credit to the original author(s) and the source, provide a link to the Creative Commons licence, and indicate if changes were made. The images or other third party material in this article are included in the article's Creative Commons licence, unless indicated otherwise in a credit line to the material. If material is not included in the article's Creative Commons licence and your intended use is not permitted by statutory regulation or exceeds the permitted use, you will need to obtain permission directly from the copyright holder. To view a copy of this licence, visit http://creativecommons.org/licenses/by/4.0/. 
neuronal susceptibility to excitability [6]. Altered homeostasis of zinc and copper may be involved in the susceptibility, development, and termination of seizures especially genetically determined epilepsy [7].

Zinc has been identified as having both proconvulsant and anticonvulsant activities [8]. It has long been established that zinc can bind to and modulate the function of a plethora of targets, including glutamate, gammaaminobutyric acid (GABA), and glycine receptors [9]. Zinc can also translocate into neurons [10], where it can modulate intracellular signaling through a host of other mechanisms.

On the other hand, copper dysregulation has an impact on synaptic transmission and excitability. Studies performed to date reveal a complex network of interconnected pathways through which copper can both serve as a signal itself and modulate signaling through multiple pathways. Copper has a unique role in oxidationreduction reactions. However, the advantages of using copper come at a price. The same reactive properties that give copper its utility as an enzymatic co-factor pose a risk for the generation of reactive oxygen species and subsequent oxidative damage in uncontrolled settings [11].

\section{Subjects and methods}

This is a case control study, where we compared serum level of zinc and copper of 100 of epileptic children visiting outpatient neurology clinics of both Ain Shams University and Helwan University hospitals in the period from October 2017 till April 2019, in addition to 50 healthy children as a control group. We included in our study the epileptic children with the age between 2 and 16 years. All parents or guardians of chosen patients and controls have provided informed written consent to participate in this study. Patients have been diagnosed according to International Leagues against Epilepsy (ILAE) definition [3]. Full history was taken from all cases including age of onset of epilepsy, predominant type of seizures, EEG findings, and duration and course of illness together with antiepileptic treatment and their response. All included cases had indefinite etiology of epilepsy. All cases had normal MRI. Yet those showed mesial temporal sclerosis were included if they had past history of febrile seizures which are supposed to be linked with low zinc serum level.

Cases were further subdivided into three subgroups. The first group included newly diagnosed cases who did not receive any medical treatment for epilepsy before time of sampling. The second group included controlled cases who are on medical treatment and seizure-free. ILAE defines seizure-free or medically responsive epilepsy as seizure freedom for 12 months or 3 times the longest previous inter-seizure interval, whichever is longer [12]. The third group included uncontrolled cases of drug-resistant epilepsy; that is defined as the failure of adequate trials of two or more tolerated, appropriately chosen, and appropriately used antiepileptic treatment regimens, whether administered as monotherapies or in combination, to achieve seizure freedom [13]. Additionally, we classified diagnosed patients who already are on medical treatment according to number of antiepileptic medications into two groups: the monotherapy and polytherapy groups.

We excluded symptomatic epilepsy due to central nervous system infections; structural, metabolic, and neurodegenerative disorders; and patients using multivitamin formula including zinc and/or copper.

A group of 50 healthy children served as controls. They were matched for gender, age, and demographic features. All control cases have normal anthropometric measurements including weight and height, and all of them are in good nutritional status with no feeding difficulties, signs of malnutrition, or vitamin deficiencies. Furthermore, all the control children were not receiving zinc- and/or copper-containing preparations or antioxidant drugs. An informed written consent was obtained from the parents/guardians of all included subjects. The study was approved by the Ethical Committee of Ain Shams University.

All the subjects were in the interictal period and at least $24 \mathrm{~h}$ seizure-free at the time of blood sampling. Serum was collected according to International Union of Pure and Applied Chemistry (IUPAC) guidelines [14]. Three milliliters of venous blood sample was collected from all patients and control in sterile silicon tubes without addition of any anticoagulants then centrifuged at $2500 \mathrm{rpm}$ for $15-20 \mathrm{~min}$. Then, the serum is collected and preserved in sterile Eppendorf tubes at $-80^{\circ}$ until the serum levels of zinc and copper were analyzed. Measurement of serum levels of zinc and copper was done by graphite furnace atomic absorption spectrometer-A Analyst 800 (PerkinElmer, USA) [14].

Laboratory values of our control candidates were compared with other international studies performed to reveal reference values of serum trace elements among pediatric populations. Used references for serum zinc and copper were determined according to the Clinical and Laboratory Standards Institute and International Federation of Clinical Chemistry guidelines. The normal reference range for serum zinc was 64-124 $\mu \mathrm{g} / \mathrm{dL}$. The reference intervals for serum copper were $75-153 \mu \mathrm{g} / \mathrm{dL}$ [15].

\section{Statistical analysis}

The data was entered to a personal computer with the aid of Microsoft Excel workbook file. Double data entry was done. Data checking for completeness and errors 
together with analysis was done using the SPSS program (Statistical Package for the Social Sciences, version 23; Chicago, USA), Student's $t$ test (a two-sample location test of the null hypothesis such that the means of two populations are equal), one sample $t$ test (a one-sample location test of whether the mean of a population has a value specified in a null hypothesis), and one-way analysis of variance (a collection of statistical models and their associated estimation procedures such as the variation among and between groups used to analyze the differences among group means in a sample). We also used Pearson's correlation coefficient (the covariance of the two variables divided by the product of their standard deviations) and linear regression module (a linear approach to modelling the relationship between a scalar response, or dependent variable, and one or more explanatory variables, or independent variables). In addition, we performed ANOVA test (based on the law of total variance, where the observed variance in a particular variable is partitioned into components attributable to different sources of variation). The cutoff value for statistical significance used in this study is a $P$ value $<0.05$.

\section{Results}

The patient group consisted of 59 males and 41 females, while there were 26 males and 24 females in the control group. Age within the studied groups ranged between 2 and 16 years. Our patients were divided into three subgroups according to the state of disease at the time of study. The mean duration of illness was 28.7 months \pm 21.7. Detailed history items among studied cases are shown in Table 1. Clinical, radiological, and EEG findings among the studied patients, together with the distribution of antiepileptic medications among patients' group, are demonstrated in Tables 2 and 3.

Serum zinc and copper of the control group were as follows: for zinc, the serum level ranged between 53.3 and $138.8 \mu / \mathrm{dL}$ with a mean of $85 \mu / \mathrm{dL} \pm 22.2$. For copper, the serum level ranged between 17.5 and $129.7 \mu / \mathrm{dL}$ with a mean of $71.6 \mu / \mathrm{dL} \pm 38.3$.

On the other hand, in patients' group, the mean zinc serum level was $59.1 \mu / \mathrm{dL} \pm 22.7$. This was lower by $30.5 \%$ when compared to the mean zinc serum level of the control group $(P<0.01)$. On measuring the copper serum level among patients' group, the mean copper serum level was $69.2 \mu / \mathrm{dL} \pm 33.6$ with no statistical significance when compared to the control group (Fig. 1).

Comparison between zinc serum levels of each of the patients' subgroups and controls showed significant lower level in each of them; with a mean of $62.7 \mu / \mathrm{dL} \pm$ $22.1,60.7 \mu / \mathrm{dL} \pm 21.6$, and $55.1 \mu / \mathrm{dL} \pm 24.3$ for newly diagnosed, controlled, and uncontrolled, respectively, compared with $85 \mu / \mathrm{dL} \pm 22.2$ in the control group $(P<$
Table 1 Distribution of different history items

\begin{tabular}{lll}
\hline $\boldsymbol{n}=100$ & Number of patients & $\%$ \\
\hline Consanguinity & 77 & 77 \\
Negative & 16 & 16 \\
Second degree & 7 & 7 \\
Higher degree & & \\
Family history & 72 & 72 \\
Negative & 28 & 28 \\
Similar condition & & \\
Past history & 69 & 69 \\
Negative & 31 & 31 \\
Other medical condition & & \\
Perinatal history & 96 & 96 \\
Negative & 4 & 4 \\
Postnatal event & & 78 \\
Developmental milestones & 78 & 2 \\
Normal & 2 & 16 \\
Delayed motor & 16 & 2 \\
Delayed speech & 2 & \\
Delayed both & 69 & \\
History of febrile seizures & & \\
Negative & & \\
Positive & & \\
\hline
\end{tabular}

Table 2 Clinical, investigational, and radiological findings of studied patients

\begin{tabular}{lll}
\hline $\mathbf{n}=100$ & $\begin{array}{l}\text { Number of } \\
\text { patients }\end{array}$ & $\%$ \\
\hline $\mathbf{s}$ & 19 & 19 \\
$\quad$ Newly diagnosed & 43 & 43 \\
$\quad$ Controlled & 37 & 37 \\
$\quad$ Uncontrolled & & \\
Semiology & 6 & 6 \\
$\quad$ Focal onset seizures & 16 & 16 \\
$\quad$ Focal onset seizures with impaired & & 78 \\
awareness & 78 & \\
Generalized seizures & & 35 \\
Interictal EEG & 35 & 37 \\
Focal discharge & 37 & 28 \\
Focal with secondary generalization & 28 & \\
Generalized discharge & & 92 \\
MRI & 92 & \\
Normal & 8 & \\
Mesial temporal sclerosis (MTS) & &
\end{tabular}


Table 3 Distribution of antiepileptic medications among patients

\begin{tabular}{lll}
\hline $\boldsymbol{n}=100$ & Number of patients & $\%$ \\
\hline Number of medication & & \\
$\quad$ Newly diagnosed patients & 19 & 19 \\
$\quad$ Patient on monotherapy & 58 & 58 \\
$\quad$ Patient on polytherapy & 23 & 23 \\
Taking medication $\boldsymbol{N}=\mathbf{8 1}$ & & \\
Levetiracetam & 44 & 54.3 \\
Carbamazepine & 22 & 27.2 \\
Oxcarbazepine & 13 & 16.0 \\
Lamotrigine & 10 & 12.3 \\
Na valproate & 9 & 11.1 \\
Ethosuximide & 9 & 11.1 \\
Zonisamide & 1 & 1.2 \\
\hline
\end{tabular}

0.05). No significant difference appeared as regards the copper serum level comparisons between patients' groups and controls, with the means of $72.4 \mu / \mathrm{dL} \pm 35.3$, $71.4 \mu / \mathrm{dL} \pm 36.3$, and $64.9 \mu / \mathrm{dL} \pm 29.6$ for newly diagnosed, controlled, and uncontrolled groups, respectively, compared with a mean of $71.6 \mu / \mathrm{dL} \pm 38.3$ for controls.

Further comparison between zinc serum levels of both newly diagnosed, receiving no treatment (19 patients), and previously diagnosed patient patients, on antiepileptic treatment at the time of the study (81 patients) showed no significant difference, where the mean was $62.7 \mu / \mathrm{dL} \pm 22.1$ in newly diagnosed cases and $58.2 \mu / \mathrm{dL}$ \pm 22.9 in previously diagnosed ones. Moreover, a comparison between estimated copper serum levels of these same groups showed no significant difference, where the mean was $72.4 \mu / \mathrm{dL} \pm 35.3$ in newly diagnosed cases and $68.4 \mu / \mathrm{dL} \pm 33.4$ in previously diagnosed ones.

Serum level of zinc and copper among controlled and uncontrolled showed insignificant lower levels in uncontrolled cases $(P>0.05)$. The mean for zinc serum level was $60.7 \mu / \mathrm{dL} \pm 21.6$ in controlled cases and $55.1 \mu / \mathrm{dL}$ \pm 24.3 in uncontrolled cases, while the mean value of copper serum level in controlled cases was $71.4 \mu / \mathrm{dL} \pm$ 36.3 and $64.9 \mu / \mathrm{dL} \pm 29.6$ in uncontrolled cases.

The mean value of zinc serum level in patients with past history of febrile seizures was $41.5 \mu / \mathrm{dL} \pm 20.1$ which was significantly lower statistically than that in patients with no history of febrile seizures with a mean value of $67.9 \mu / \mathrm{dL} \pm 19.3$. However, the mean value of copper serum level among patients with history of febrile seizures was not statistically different from that of patients without history of febrile seizures (Fig. 2).

By using correlation coefficient between patients' mean level of zinc and copper with duration of illness in months, a negative correlation was noted only between copper serum level and duration of illness, which means the longer the duration of illness the lower the copper serum level $(R=0.213, P=0.03)$ as shown in (Fig. 3). However, it was not the case for zinc $(R=0.081, P=0.4)$

Estimated mean value of zinc and copper serum level among patients showing mesial temporal sclerosis (MTS) in MRI was lower by 27.6 and $37.2 \%$, respectively. This difference was statistically insignificant $(P=0.07)$ for zinc but was not for copper (Table 4).

Regarding the effect of medications, a lower mean value of serum level of both zinc and copper among 58 patients on monotherapy was found compared to that of 23 patients on polytherapy, yet the difference was not significant statistically $(P>0.05)$. The mean zinc level was $56.2 \mu / \mathrm{dL} \pm 21.5$ and $63.1 \mu / \mathrm{dL} \pm 26.1$ in patients on monotherapy and those on polytherapy, respectively. The mean copper level was $65.6 \mu / \mathrm{dL} \pm 34.6$ and $75.5 \mu /$ $\mathrm{dL} \pm 29.5$ in patients on monotherapy and those on polytherapy, respectively.

Levetiracetam was found to be the most used medication among our studied patients' group (44\%). When the mean serum levels of both zinc and copper were studied among these patients, they were slightly higher compared to those of the rest of patients not receiving levetiracetam, yet with no statistical significance (Table 5). On the other hand, when the zinc mean levels of patients on

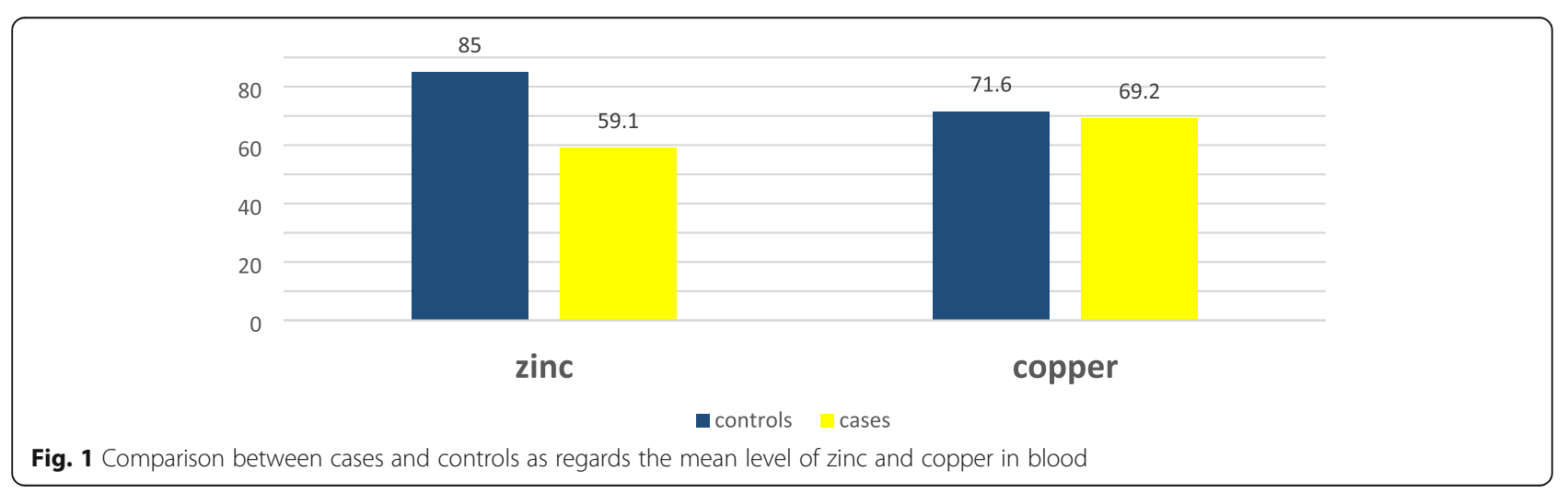




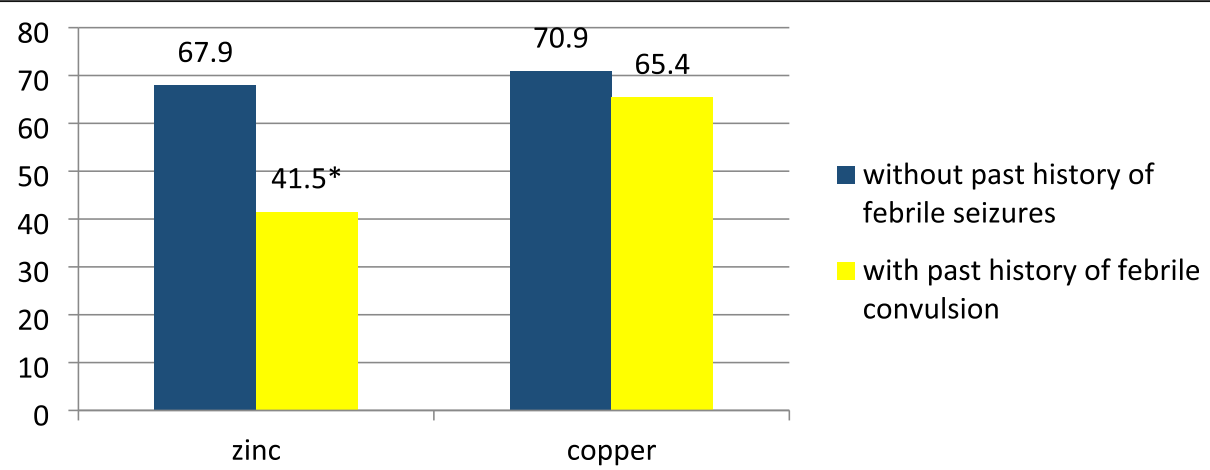

Fig. 2 Comparison between patients with positive and negative history of febrile seizures as regards zinc and copper levels

levetiracetam was compared to those of control subjects, it was lower, yet again the difference was not significant.

Carbamazepine was the second commonly used medication (22\% of patients). The mean level of zinc serum level of patients on carbamazepine showed significantly lower level compared to those not receiving carbamazepine. Moreover, this mean value was significantly at lower level when compared to the mean value of the control group $(P=0.01$; Fig. 4$)$. The mean value of serum copper among same patients' group was lower than those did not receive carbamazepine, yet with no statistical significance (Table 6).

By using linear regression model for the factors independently related to the zinc level in serum among the studied cases, it was found that the past history of febrile seizures, generalized epileptic discharge in EEG, and carbamazepine intake were strongly associated with lower zinc serum level (Table 7).

\section{Discussion}

The exact pathogenesis of epilepsy is not fully understood yet. However, there are studies suggesting that the body electrolytes and the level of some trace elements may have a crucial role in epileptogenesis. This is due to increased free radicals or decreased antioxidant defense mechanisms that have been causally involved in some forms of epilepsies and contribute to pathophysiology of neuronal excitability, neuronal excitotoxicity, seizure recurrence, and resistance to antiepileptic medications. In addition, seizures are followed by significant alterations in both intra- and extra-cellular ion concentrations $[16,17]$.

In our study, we chose to measure zinc and copper serum levels in epileptic children and compare them with matched age and sex healthy controls. Assessment of zinc and copper status is dependent on the quantification of total zinc and copper concentrations in serum $[18,19]$. It is the most widely used laboratory tests for diagnosis of severe deficiency and to monitor adequacy of provision [20].

In the present study, we found that levels of serum zinc observed in pediatric epileptic patients were 30\% lower than those of healthy controls $(P<0.001)$. Our results are in accordance with the previous studies, where significant lower levels of serum zinc have been reported in epileptic patients [21-23]. We found significant difference when we compared zinc serum level of newly diagnosed, controlled, and uncontrolled patients' groups on one side and zinc serum level of the control group on the other side with $P<0.05$ for the three patients' groups. Same results came from the previous studies that compared zinc serum level between uncontrolled

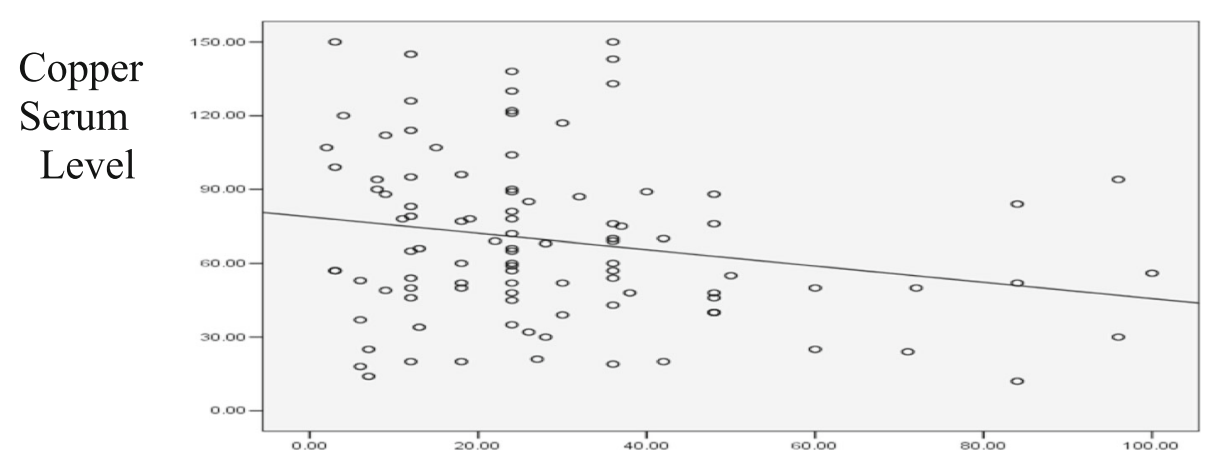

Fig. 3 Correlation coefficient showed negative correlation between copper serum level and duration of illness in months 
Table 4 Comparison between patients with and without mesial temporal sclerosis in MRI

\begin{tabular}{|c|c|c|c|c|}
\hline & $\begin{array}{l}\text { Patients with MTS } \\
N=8 \\
\text { Mean SD }\end{array}$ & $\begin{array}{l}\text { Patients without MTS } \\
N=92 \\
\text { Mean SD }\end{array}$ & $t$ & $P$ \\
\hline Zinc $(\mu / d L)$ & $47.1 \pm 17.0$ & $60.1 \pm 22.9$ & 2.0 & $0.07^{*}$ \\
\hline Copper $(\mu / d L)$ & $51.5 \pm 39.2$ & $70.7 \pm 32.9$ & 1.5 & 0.1 \\
\hline
\end{tabular}

MTS mesial temporal sclerosis

*Insignificant

epileptic patients and healthy controls [24, 25]. Only one study found no significant difference in serum zinc between epileptic cases and controls [26].

This significant difference could be explained by zinc's capability to modulate the neuronal excitability. Low zinc serum level may enhance seizure activity by inhibiting the inhibitory neurotransmitter, GABA, or by defective production of superoxide dismutase and glutathione peroxidase. Hypozincemia activates $N$-methyl-D-aspartate (NMDA) receptors which may play an important role in the induction of epileptic discharge [27]. However, the role of zinc in seizures is still controversial as it has a role in the synthesis and function of inhibitory neurotransmitter, GABA, at one hand and it also shows an inhibitory effect on GABA on the other hand and thus facilitates seizure activity [28].

In our study, there was no significant difference when the serum zinc level of newly diagnosed, untreated patients was compared with that of previously diagnosed patients on medical treatment. This was opposite to what other studies revealed. They found that zinc level in serum and hair was significantly lower in patients treated with antiepileptic therapies, either mono- or polytherapy, than in untreated patients $[29,30]$. Farahani and colleagues and Wojciak and colleagues had found that zinc serum level was significantly decreased in controlled (on monotherapy) epileptic patients than in untreated patients $[16,21]$. The discrepancy between our study and others' results might be due to the relatively small number of newly diagnosed patients in comparison to their number in the abovementioned studies.

Antiepileptic drugs may be involved in lowering serum zinc levels. In our study, we had 22 patients receiving carbamazepine. They showed significant lower zinc serum level in comparison to both controls and patients who received other antiepileptics. This goes in accordance with other study results [23, 31]. However, other authors found normal serum zinc in epileptic patients after 1 year treatment with carbamazepine [28, 32]. Another study included 40 epileptic patients and 31 healthy children between 4 and 12 years of age, where serum carbamazepine level, total antioxidant capacity, and total oxidant status were measured. Oxidative stress index was also calculated in both patients and controls. Results showed that the epileptic group had decreased levels of total antioxidant capacity, increased total oxidative stress, and high oxidative stress index levels. In addition, positive correlation between plasma carbamazepine levels and total oxidant status was observed. That means that carbamazepine has no antioxidant effect and may have a role in oxidant status [33].

In our study, there were 44 patients on levetiracetam treatment who showed no significant difference in their zinc serum level in comparison to both the rest of patients who were not on levetiracetam and the controls. This was not the case with what Sarangi and colleagues found. Their study showed that patients on levetiracetam had quit higher zinc serum level in comparison to controls [34]. They attributed their findings to increased absorption of metals from the gastrointestinal tract or decreased elimination from the body. Levetiracetam has minimal metabolism with no cytochrome-P450 isoenzyme inducing potential; hence, its pharmacokinetics may have less causative role in affecting the trace element level than its pharmacodynamics aspects, which needs to be analyzed [35]. Well, in our study, the absence of significant difference in zinc level between patients on levetiracetam and those who are not may be attributed to the effect of other antiepileptics received as some of them were on polytherapy including levetiracetam, while the abovementioned study included patients on levetiracetam only as a monotherapy.

Febrile seizures, as one of the most common seizure syndromes in children, is an important item to be observed. They may be associated with more severe forms of epilepsy in later life, with long-term studies indicating

Table 5 Comparison between patient with and without levetiracetam intake as regards zinc and copper serum levels

\begin{tabular}{lllr} 
& $\begin{array}{l}\text { Patients on levetiracetam } \\
n=44\end{array}$ & $\begin{array}{l}\text { Patients not on levetiracetam } \\
n=56\end{array}$ & $\boldsymbol{P}$ \\
& Mean SD & Mean SD & \\
\hline Zinc $(\mu / \mathrm{dL})$ & $61.8 \pm 25.6$ & $56.9 \pm 20.1$ & 1.0 \\
Copper $(\mu / \mathrm{dL})$ & $75.3 \pm 33.4$ & $64.4 \pm 33.4$ & 1.6 \\
\hline
\end{tabular}


Table 6 Comparison between patients with and without carbamazepine intake as regards mean zinc and copper serum level

\begin{tabular}{llll} 
& $\begin{array}{l}\text { Patient on carbamazepine } \\
\boldsymbol{n}=22 \\
\text { Mean SD }\end{array}$ & $\begin{array}{l}\text { Patients not on carbamazepine } \\
\boldsymbol{n}=78 \\
\text { Mean SD }\end{array}$ & $\boldsymbol{t}$ \\
\hline Zinc $(\mu / \mathrm{dL})$ & $49.0 \pm 17.0$ & $61.8 \pm 23.4$ & 2.8 \\
Copper $(\mu / \mathrm{dL})$ & $66.7 \pm 34.3$ & $69.9 \pm 33.6$ & 0.3 \\
\hline
\end{tabular}

$(P<0.01)$

* highly significant

that $7 \%$ of children with febrile seizures subsequently develop epilepsy [36]. In our study, epileptic patients with past history of febrile seizures showed significant decrease in zinc serum level in comparison to patients without history of febrile seizures. This agreed with previous studies which revealed low zinc serum level in children with febrile seizures in comparison with controls [37-40] and in comparison with children who had acute febrile illness without febrile seizures [41]. Several studies support the idea that low zinc levels increase seizure susceptibility. They found that zinc levels are significantly lower in the blood of children that suffer febrile seizures, both when compared to healthy controls and when compared to children either presenting with fever alone or seizures not associated with fever [42, 43]. These studies highlight the dysfunction of zinc homeostasis as a potential mechanism of enhanced febrile seizure susceptibility.

On the other hand, copper can act on various types of ion channels, including NMDA receptors and voltagegated calcium channels, which are important contributors to neuronal excitability and synaptic communication [44]. The present study showed no significant difference in serum copper in epileptic patients compared to healthy controls $(P=0.6)$. This is in accordance with some previous studies $[24,25]$. In other studies, the copper serum level of epileptic patients' group appeared higher than that of healthy groups [16, 22, 45]. Hamed and colleagues found lower serum copper in epileptic patients compared with the controls [29]. Well, we considered that our control subjects had lower serum level of copper in comparison to available pediatric intervals established by other nations' studies. We might get valued difference in serum copper between epileptic patients and controls if we had greater number of controls who may show a higher level of copper in serum.

In our study, no significant difference was found between copper serum levels of newly diagnosed, untreated patients, and previously diagnosed, and treated ones, which was opposite to Saboktakin and colleagues' findings. They found that serum copper was significantly higher in treated patients' group than in the untreated group [31]. We also found that the serum level of copper showed no significant difference between patients on monotherapy and others on polytherapy. Again, other studies found that the serum copper was higher in patients on polytherapy treatments compared in patients on monotherapy $[31,45,46]$. All these studies included patients on phenytoin antiepileptic drug that was accused as the main cause of elevated serum copper in treated patients' group, yet our study did not include any patient with phenytoin intake.

We did not find any significant difference in copper serum level between patients on either carbamazepine or levetiracetam on hand and patients who were not on these medications and control on the other hand. Hamed and colleagues cited reduction in copper level with carbamazepine intake [29]. Reduced level with carbamazepine intake was attributed to enhanced biliary excretion of copper; however, this study included more patients on carbamazepine than ours [34].

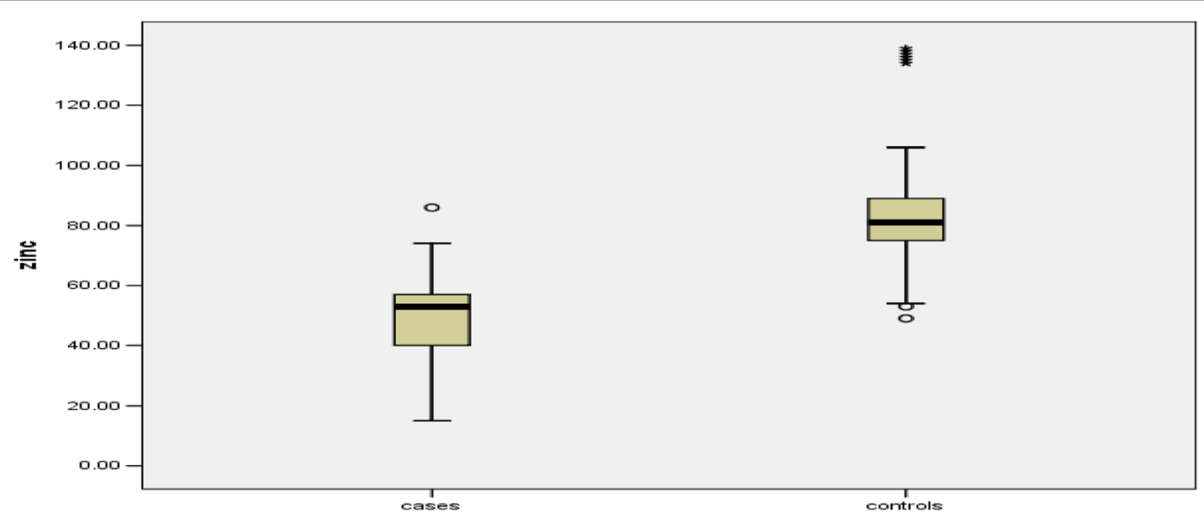

Fig. 4 Comparison between mean value of zinc serum level in patients with carbamazepine intake and control group 
Table 7 Linear regression model for the factors independently related to the zinc level in serum among cases

\begin{tabular}{llll}
\hline Factor & Standard B & $\boldsymbol{t}$ & $\boldsymbol{P}$ \\
\hline Polytherapy & 0.04 & 0.5 & 0.5 \\
Generalized EEG discharge & -0.256 & 3.0 & $\mathbf{0 . 0 0 0}$ \\
Febrile seizures & -0.502 & 5.8 & $\mathbf{0 . 0 0 0}$ \\
Carbamazepine intake & -0.216 & 2.4 & $\mathbf{0 . 0 1}$ \\
Mesial temporal sclerosis in MRI & -0.04 & 0.4 & 0.6 \\
\hline
\end{tabular}

In our study, patients with past history of febrile seizures had no significant difference in their copper serum level in comparison to those without febrile seizures in their past history. Other studies showed that patients with febrile seizures had statistically higher serum copper concentrations than patients with febrile illness without seizures [47]. However, they included bigger sample size than ours.

Finally, our study had revealed a negative relationship between copper serum level and duration of epilepsy illness. In other words, the longer duration of the epilepsy disease is accompanied with a lower serum level of copper. However, it could be attributed to prolonged use of antiepileptic drugs that alter intestinal absorption, excretion methods, and distribution within body tissues.

\section{Conclusion}

Our results suggest that lower levels of serum zinc have a strong link with both febrile seizures and epilepsy. Carbamazepine intake is better be accompanied with zinc supplement due to associated lower zinc levels compared with other antiepileptic drugs. Altered copper level among epileptic patients may result from longterm use of antiepileptic drugs. Management plan of epileptic patients that preserves normal serum level of zinc and copper might be more effective in seizure control.

\section{Abbreviations}

EEG: Electroencephalography; GABA: Gamma-aminobutyric acid: ILAE: International League Against Epilepsy; IUPAC: International Union of Pure and Applied Chemistry; MRI: Magnetic resonance imaging; MTS: Mesial temporal sclerosis; NMDA: N-Methyl-D-aspartate

\section{Acknowledgments}

Not applicable

\section{Authors' contributions}

NA and ME made substantial contributions to the conception and design of the study; ME performed the acquisition of data; all authors participated in the analysis and interpretation of data; ME and KA have been involved in drafting the manuscript or revising it critically for important intellectual content; NA has given final approval of the version to be published. All authors agreed to be accountable for all aspects of the work in ensuring that questions related to the accuracy or integrity of any part of the work are appropriately investigated and resolved.

\section{Funding}

None

\section{Availability of data and materials}

The datasets generated and analyzed during the current study are not publicly available due to institutional limitations, yet they are available from the corresponding author on reasonable request.

\section{Ethics approval and consent to participate}

This study was approved by the ethical committee of Ain Shams University School of Medicine on the 10th of September 2017. All parents/guardians of the chosen subjects and controls provided informed written consent prior to participating in any study-related activities.

Consent for publication

Not applicable

\section{Competing interests}

The authors declare that they have no competing interests.

\section{Author details}

${ }^{1}$ Departemnt of Neurology and Psychiatry, Helwan University School of Medicine, Cairo, Egypt. ${ }^{2}$ Department Neurology and Psychiatry, Faculty of Medicine Ain Shams University, Cairo, Egypt. ${ }^{3}$ Department Community and Occupational Medicine, Faculty of Medicine Ain Shams University, Cairo, Egypt.

Received: 14 April 2020 Accepted: 3 July 2020

Published online: 23 July 2020

\section{References}

1. Fiest KM, Sauro KM, Wiebe S, Patten SB, Kwon CS, Dykeman J, et al. Prevalence and incidence of epilepsy: a systematic review and meta-analysis of international studies. Neurology. 2017;88:296-303.

2. Hesdorffer DC, Beck V, Begley CE. Research implications of the Institute of Medicine Report, Epilepsy Across the Spectrum: promoting health and understanding. Epilepsia. 2013;54:207-16.

3. Cowan LD. The epidemiology of the epilepsies in children. Ment Retard Dev Disabil Res Rev. 2002:8:171-81.

4. Kanemura H, Mizorogi S, Aoyagi K, Sugita K, Aihara M. EEG characteristics predict subsequent epilepsy in children with febrile seizure. Brain Dev. 2012 ; 34:302-7.

5. Scheffer IE, Berkovic S, Capovilla G, Connolly MB, French J, Guilhoto L, et al. ILAE classification of the epilepsies: position paper of the ILAE Commission for Classification and Terminology. Epilepsia. 2017;58:512-21.

6. Hamed SA, Abdellah MM, El-Melegy N. Blood levels of trace elements, electrolytes, and oxidative stress/antioxidant systems in epileptic patients. J Pharmacol Sci. 2004;96:349-59.

7. Seven M, Basaran SY, Cengiz M, Unal S, Yuksel A. Deficiency of selenium and zinc as a causative factor for idiopathic intractable epilepsy. Epilepsy Res. 2013;104:35-9.

8. Gower-Winter SD, Levenson CW. Zinc in the central nervous system: from molecules to behavior. Biofactors. 2012;38:186-93.

9. Smart TG, Hosie AM, Miller PS. Zn2+ ions: modulators of excitatory and inhibitory synaptic activity. Neuroscientist. 2004;10:432-42.

10. Aiba I, West AK, Sheline CT, Shuttleworth CW. Intracellular dialysis disrupts $\mathrm{Zn} 2+$ dynamics and enables selective detection of $\mathrm{Zn} 2+$ influx in brain slice preparations. J Neurochem. 2013;125:822-31.

11. Andreini C, Banci L, Bertini I, Rosato A. Occurrence of copper proteins through the three domains of life: a bioinformatic approach. J Proteome Res. 2008;7:209-16.

12. Kwan P, Arzimanoglou A, Berg AT, Brodie MJ, Allen Hauser W, Mathern G, et al. Definition of drug-resistant epilepsy: consensus proposal by the ad hoc Task Force of the ILAE Commission on Therapeutic Strategies. Epilepsia. 2010;51:1069-77.

13. Kwan P, Schachter SC, Brodie MJ. Drug-resistant epilepsy. N Engl J Med. 2011;365:919-26.

14. Bolann BJ, Rahil-Khazen R, Henriksen H, Isrenn R, Ulvik R. Evaluation of methods for trace-element determination with emphasis on their usability in the clinical routine laboratory. Scand J Clin Lab Invest. 2007:67:353-66.

15. Lin CN, Wilson A, Church B, Ehman S, William R, Mcmillin G. Pediatric reference intervals for serum copper and zinc. Clin Chim Acta. 2012;413: $612-5$. 
16. Wojciak RW, Mojs E, Stanislawska-Kubiak M, Samborski W. The serum zinc, copper, iron, and chromium concentrations in epileptic children. Epilepsy Res. 2013;104:40-4.

17. Bush Al. Metals and neuroscience. Curr Opin Chem Biol. 2000;4:184-91.

18. Bertinato J, Zouzoulas A. Considerations in the development of biomarkers of copper status. J AOAC Int. 2009:92:1541-50.

19. Gibson RS, Hess SY, Hotz C, Brown KH. Indicators of zinc status at the population level: a review of the evidence. Br J Nutr. 2008;99(Suppl. 3):S14-23.

20. Brown KH, Peerson JM, Rivera J, Allen LH. Effect of supplemental zinc on the growth and serum zinc concentrations of pre-pubertal children: a metaanalysis of randomized controlled trials. Am J Clin Nutr. 2002;75:1062-71.

21. Farahani HN, Ashthiani AR, Masihi MS. Study on serum zinc and selenium levels in epileptic patients. Neurosciences (Riyadh). 2013;18:138-42.

22. Prasad DK, Shaheen U, Satyanarayana U, Surya Prabha T, Jyothy A, Munshi A. Association of serum trace elements and minerals with genetic generalized epilepsy and idiopathic intractable epilepsy. Neurochem Res. 2014;39:2370-6.

23. Talat MA, Ahmed A, Mohammed L. Serum levels of zinc and copper in epileptic children during long-term therapy with anticonvulsants. Neurosciences (Riyadh). 2015;20:341-5.

24. Kheradmand Z, Yarali B, Zare A, Pourpak Z, Shams S, Ashrafi MR. Comparison of serum zinc and copper levels in children and adolescents with intractable and controlled epilepsy. Iran J Child Neurol. 2014;8:49-54.

25. Saad K, Hammad E, Hassan AF, Badry R. Trace element, oxidant and antioxidant enzyme values in blood of children with refractory epilepsy. Int J Neurosci. 2014;24:181-6.

26. Ithan A, Ozerol E, Güleç M, Işik B, Ilhan N, Ihan N, et al. The comparison of nail and serum trace elements in patients with epilepsy and healthy subjects. Prog Neuropsychopharmacol Biol Psychiatry. 2004;28:99-104.

27. Frazzini $V$, Rockabrand E, Mocchegiani E, Sensi SL. Oxidative stress and brain aging: is zinc the link? Biogerontology. 2006;7:307-14.

28. Mishra OP, Singhal D, Upadhyay RS, Prasad R, Atri D. Cerebrospinal fluid zinc, magnesiuim, copper and gamma-aminobutyric acid levels in febrile seizure. J Pediatr Neurol. 2007;5:39-44.

29. Hamed SA, Abdellah MM, El-Melegy N. Blood levels of trace elements, electrolytes, and oxidative stress/antioxidant systems in epileptic patients. J Pharmacol Sci. 2004;96:465-73.

30. Doneray H, Kara IS, Karakoc A, Tan H, Orbak Z. Serum thyroid hormone profile and trace elements in children receiving valproic acid therapy: a longitudinal and controlled study. J Trace Elem Med Biol. 2012;26:243-7.

31. Saboktakin L, Barzegar M, Jo A, Emamalizadeh M. Study on serum copper and zinc level of children with epilepsy during long term therapy with anticonvulsants. Life Sci J. 2012;9:1250-4.

32. Verrotti A, Basciani F, Trotta D, Pomilio MP, Morgese G, Chiarelli F. Serum copper, zinc, selenium, glutathione peroxidase and superoxide dismutase levels in epileptic children before and after 1 year of sodium valproate and carbamazepine therapy. Epilepsy Res. 2002;48:71-5.

33. Tutanc M, Aras M, Dokuyucu R, Altas M, Zeren C, Arica V, et al. Oxidative status in epileptic children using carbamazepine. Iran J Pediatr. 2015;25:e3885.

34. Sarangi SC, Tripathi M, Kakkar AK, Gupta YK. Effect of antiepileptic therapy on trace elements status in Indian population in a tertiary care hospital from northern India: a cross sectional study. Epilepsy Res. 2014;108:917-27.

35. Lyseng-Williamson KA. Levetiracetam: a review of its use in epilepsy. Drugs. 2011;71:489-514.

36. Hildebrand MS, Phillips AM, Mullen SA, Adlard PA, Hardies K, Damiano JA, et al. Loss of synaptic Zn2+ transporter function increases risk of febrile seizures. Sci Rep. 2015;5:17816.

37. Akarsu S, Yilmaz S, Ozan S, Kurt A, Benzer F, Gurgoze MK. Effects of febrile and afebrile seizures on oxidant state in children. Pediatr Neurol. 2007;36:307-11.

38. Amiri M, Farzin L, Moassesi ME, Sajadi F. Serum trace element levels in febrile convulsion. Biol Trace Elem Res. 2010;135:38-44.

39. El-Masry HMA, Sadek AA, Hassan MH, Ameen HH, Ahmed HA. Metabolic profile of oxidative stress and trace elements in febrile seizures among children. Metab Brain Dis. 2018;33:1509-15.

40. Gunes S, Dirik E, Yis U, Seckin E, Kuralay F, Kose $S$, et al. Oxidant status in children after febrile seizures. Pediatr Neurol. 2009;40:47-9.

41. Vidyasagar V, Venugopal BL, Darshan MS. Comparison of serum zinc level in patients with simple febrile seizure versus acute febrile illness. Sch J App Med Sci. 2015;3:2210-9.
42. Blasco-lbáñez JM, Poza-Aznar J, Crespo C, Marqués-Marí Al, Gracia-Llanes FJ, Martínez-Guijarro FJ. Chelation of synaptic zinc induces over excitation in the hilar mossy cells of the rat hippocampus. Neurosci Lett. 2004; 355:101-104.

43. Waqar Rabbani M, Ali I, Zahid Latif H, Basit A, Rabbani MA. Serum zinc level in children presenting with febrile seizures. Pak J Med Sci. 2013;29:1008-11.

44. Schlief ML, Craig AM, Gitlin JD. NMDA receptor activation mediates copper homeostasis in hippocampal neurons. J Neurosci. 2005;25:239-46.

45. Ulvi H, Yigiter R, Yoldas T, Dolu Y, Var A, Mungen B. Zinc and copper contents in hair and their serum concentrations in patients with epilepsy. Eastern J Med. 2002;7:31-5.

46. Helal SI, Megahed HS, Salem SM, Youness ER. Monotherapy versus polytherapy in epileptic adolescents. Maced J Med Sci. 2013;6:174-7.

47. Saghazadeh A, Mahmoudi M, Meysamie A, Gharedaghi M, Zamponi GW, Rezaei N. Possible role of trace elements in epilepsy and febrile seizures: a meta-analysis. Nutr Rev. 2015;73:760-79.

\section{Publisher's Note}

Springer Nature remains neutral with regard to jurisdictional claims in published maps and institutional affiliations.

\section{Submit your manuscript to a SpringerOpen ${ }^{\circ}$ journal and benefit from:}

- Convenient online submission

- Rigorous peer review

- Open access: articles freely available online

High visibility within the field

- Retaining the copyright to your article

Submit your next manuscript at $\boldsymbol{\sim}$ springeropen.com 